Психология. Журнал Высшей школы экономики.

2021. T. 18. № 2. C. 402-415. DOI: 10.17323/1813-8918-2021-2-410-423

\title{
ПОСТМОДЕРНИЗМ В ПСИХОЛОГИИ: БИБЛИОМЕТРИЧЕСКИЙ АНАЛИЗ
}

\author{
А.А. ФЁДОРОВ \\ ${ }^{a}$ Новосибирский государственный университет, 630090, Россия, Новосибирск, ул. Пирогова, д. 1
}

\begin{abstract}
Резюме
В статье проведен библиометрический анализ психологических публикаций, индексированных в Scopus, в которых либо обсуждается постмодернизм (как в позитивном, так и негативном ключе), либо привлекаются его идеи для анализа тех или иных явлений. Для анализа и визуализации полученных результатов использовалась свободно распространяемая программа VOSviewer. Всего для отрасли знания «Психология» было идентифицировано 1892 документа. Показано, что «локусом проникновения» постмодернизма в психологическую науку можно считать психоанализ. Начиная с 1997 г. количество психологических публикаций, связанных с постмодернизмом, стабилизировалось в диапазоне от 60 до 80 в год. При помощи построения понятийной карты на основе анализа ключевых слов выделены шесть тематических кластеров, анализ которых показывает, что основными психологическими направлениями, в которых используются постмодернистские идеи, являются психоанализ и социальный конструкционизм. Три страны (США, Великобритания и Канада) генерируют практически $2 / 3$ количества психологических публикаций (61.8\%), имеющих отношение к постмодернизму. Наиболее цитируемый и эффективный автор в этой области - К. Герген. Сделан вывод о том, что хотя взрывной рост психологических публикаций, посвященных постмодернизму, закончился, этот феномен продолжает вызывать устойчивый, хотя и несколько угасший интерес исследователей в различных областях психологии. Вопрос о том, можно ли рассматривать постмодернистскую психологию вообще как манифестацию постнеклассической рациональности, остается открытым, но наукометрический анализ показывает, что постнеклассика сама по себе в психологических публикациях, связанных с постмодернизмом, представлена весьма незначительно.
\end{abstract}

Ключевые слова: библиометрический анализ, постмодернизм, постнеклассическая психология, социальный конструкционизм, наукометрия.

В настоящее время библиометрические исследования переживают взрывной рост, в том числе благодаря развитию современных компьютерных технологий, а научная деятельность конкретного ученого включает в себя не только (и часто не столько) пресловутый поиск истины, но и борьбу за рост собственных наукометрических показателей. Очевидно, однако, что библиометрические техники, являясь весьма мощным инструментом количественной оценки ситуации в определенной научной области, обладают рядом ограничений и не

Работа выполнена при финансовой поддержке РФФИ в рамках научного проекта № 18-013-00715. 
могут заменить собой содержательный анализ. Представляется, что бо́льшую пользу принесла бы открытая научная дискуссия, посвященная обсуждению возможностей и ограничений библиометрических и иных наукометрических методов в психологии.

\section{Введение}

Споры о роли постмодернизма в психологии не утихают с момента публикации в 1990 г. статьи К. Гергена, в которой он провозгласил постмодернистский поворот в психологии (Gergen, 1990). Уже в 1998 г. Й. Паркер высказывал опасения по поводу того, что этот «постмодернистский» поворот может трансформироваться в нечто худшее, и утверждал, что «постмодернизм пережил свою полезность» (Parker, 1998, p. 603). И хотя ряд исследователей продолжают отстаивать продуктивность постмодернизма в современной психологии, в настоящее время споры о нем переместились скорее в историческую плоскость. Так, М.С. Гусельцева, ранее соотносившая постнеклассическую рациональность с постмодернизмом, в последних своих работах пишет о том, что он устарел, а ему на смену пришел «метамодернизм» (Гусельцева, 2016, 2018). Е.Ю. Патяева не только утверждает, что это соотнесение возможно, но и говорит о том, что «постмодернистский стиль мышления представляет собой более сильную, последовательную и расширенную версию постнеклассического идеала рациональности» (Патяева, 2018, с. 176). Так или иначе развитие психологии в конце XX - начале XXI в. во многом было связано с противостоянием модернизма и постмодернизма. В каком-то смысле окончательная победа последнего означала бы смерть мечты о психологии как классической науке. Это противостояние еще не закончено, и существуют достаточные причины полагать, что метамодернизм представляет собой лишь еще один лик постмодернизма, маркетинговый трюк, направленный на то, чтобы вновь попытаться внедрить в психологию постмодернистские идеи. Как бы то ни было, оценка вклада постмодернизма в развитие психологической науки (или вреда, который он ей нанес) остается актуальной. Большую помощь в такой оценке могут оказать современные библиометрические методы, опирающиеся на количественный анализ и позволяющие составить наукометрическую «карту» определенной научной области. Отметим, что в современной психологии библиометрические техники используются в самых различных областях. Например, в 2018 г. было опубликовано исследование, в котором обсуждалось развитие психологии как дисциплины на основе библиометрического анализа 676393 статей, индексированных в базе PsycINFO (Flis, van Eck, 2018). С помощью библиометрии изучались публикации, посвященные психологии морали (Ellemers et al., 2019), психологии потребителя (Jia et al., 2018), психологии социальных медиа (Zyoud et al., 2018), школьной психологии (Liu, Oakland, 2016) и пр. Библиометрические техники могут использоваться как для анализа отдельных психологических журналов (Kozlowski et al., 2017; Pesta, 2018; Tur-Porcar et al., 2018), так и для изучения 
публикаций психологов различных стран, например России (Ловаков, 2017) или Чили (Polanco-Carrasco et al., 2017).

Цель настоящего исследования - провести библиометрический анализ психологических публикаций, в которых либо обсуждается постмодернизм (как в позитивном, так и негативном ключе), либо привлекаются его идеи для анализа тех или иных явлений. Укажем, что ранее нами были изучены статьи, индексированные в базе Scopus, которые так или иначе связаны с постнеклассической психологией (Фёдоров, 2018a). Согласно одному из выводов, постнеклассическая психология как таковая - исключительно феномен российской науки. Однако если признать корректность упомянутого выше соотнесения постнеклассической рациональности и постмодернизма, то открывается возможность для взгляда, согласно которому за рубежом постнеклассическая психология манифестирована в постмодернистских публикациях. Обсуждение корректности такого соотнесения, однако, выходит за рамки данной статьи'. Более того, в настоящем исследовании нами будут проанализированы не только те публикации, которые можно отнести собственно к постмодернистским, но и те, в которых постмодернизм критикуется.

\section{Материалы и методы}

Данные для исследования извлекались 20 марта 2019 г. из библиографической базы данных Scopus, которая охватывает на $20 \%$ больше источников, чем Web of Science (Falagas et al., 2008).

Поисковый запрос был записан следующим образом: TITLE-ABSKEY(postmodern* OR post-modern*) AND PUBYEAR $<2019$ AND (LIMITTO (SUBJAREA, «PSYC»)). Иными словами, поиск производился по всем типам документов в названии статьи, аннотации и/или ключевых словах в отрасли знания «Психология» на основе слов «postmodern*» и «post-modern*» (некоторые авторы предпочитают использовать приставку «post» c дефисом). Также была создана вторая база текстов, в которой не было спецификации отрасли знания. Учитывались статьи, опубликованные по 2018 г. включительно. Для предметной области «Психология» было найдено 1892 документа, соответствующих условиям поиска, из них (по параметру «SOURCE TYPE») 1687 - журнальные публикации разных типов (статьи, обзоры и пр.), 191 - книги (включая книжные серии), 14 - материалы конференций. Для сравнения аналогичный поисковый запрос в базе данных Web of Science (TS=(postmodern* OR post-modern*) AND SU=psychology AND $\mathrm{PY}=(1950-2018))$ идентифицирует 1175 документов. Таким образом, преимущество базы данных Scopus перед Web of Science в контексте задач настоящей статьи заключается в том, что она содержит значительно больше источников, удовлетворяющих критериям поиска.

\footnotetext{
${ }^{1}$ Можно отметить, что во введении к сборнику статей отечественных методологов психологии говорится о «характерных для постнеклассической науки постмодернистских веяниях в психологии» (Журавлев, Юревич, 2007, с. 9).
} 
Построение библиометрической карты проводилось в программе VOSviewer, версия 1.6.10. С помощью этого открытого программного обеспечения можно визуализировать данные, опираясь на анализ таких параметров, как совместная встречаемость терминов, соавторство, цитирование и пр. Метод визуализации сходств, который лежит в основе VOSviewer, позволяет, по словам разработчиков программы, создавать более структурированные карты, чем некоторые другие методы (van Eck, Waltman, 2010).

\section{Результаты и обсуждение}

\section{Временни́е трендъ}

Динамика публикаций, проиндексированных в базе Scopus, которые относятся к предметной области «Психология» и в названии, аннотации и/или ключевых словах которых содержится указание на постмодернизм, отражена на рисунке 1.

Хотя первая обнаруженная публикация вышла в 1978 г., содержательно она мало связана с психологической наукой и посвящена обсуждению «постмодернистской» утопии расселения людей в космическом пространстве (Russell, 1978). Фактически, первая работа, в которой обсуждается значение постмодернизма для психологии, выходит только в 1986 г. В ней С. Тулмин отстаивает тезис, согласно которому «в большей или меньшей степени, все ветви психологии являются скорее постмодернистскими, нежели классическими или модернистскими науками. И особенно это верно в отношении психоанализа» (Toulmin, 1986, р. 468). Таким образом, «локусом проникновения» постмодернизма в психологическую науку можно считать психоанализ. С этого года начинается постоянный рост количества психологических публикаций, затрагивающих постмодернизм, при этом в качестве переломного можно

Рисунок 1

Динамика психологических публикаций, касающихся постмодернизма (1978-2018)

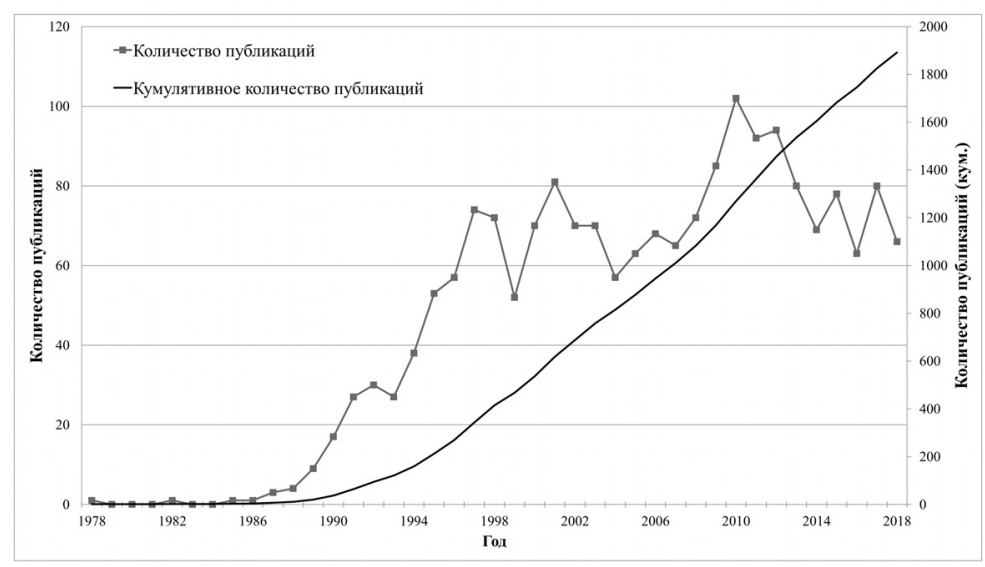


рассматривать 1990 г., когда выходит упоминавшаяся ранее статья К. Гергена «На пути к постмодернистской психологии» (Gergen, 1990). Начиная с 1997 г. количество таких публикаций стабилизируется в диапазоне от 60 до 80 в год с небольшим всплеском в период с 2009 по 2012 г. Среднее число публикаций $(\mu \Pi)$, выходящих в год, в период с 1997 по 2018 г. составляет 77.8.

\section{Понятийная карта}

Как уже указывалось выше, библиометрическая карта строилась в программе VOSviewer. Понятия, прямо указывающие на постмодернизм (postmodern, postmodernism, post-modern, post-modernism, postmodernity, postmodernity), исключались, так как предметная область исследования была очерчена самой логикой построения базы. Термины (1) career counselling и career counseling; (2) counselling и counseling рассматривались как синонимичные. Минимальный порог совместной встречаемости авторских ключевых слов был равен семи. В ходе проведенного отбора из 3286 слов осталось 65. В качестве метода нормализации использовалась фракционализация, поскольку в данном случае она давала чуть более осмысленное решение, нежели нормализация методом силы связи.

Построенная понятийная карта приведена на рисунке 2. Частота встречаемости терминов на этой библиометрический карте отражена площадью кругов, а чем ближе расположены круги по отношению друг к другу, тем чаще соответствующие термины встречаются совместно. Отдельные кластеры обозначены разными цветами․․

Понятия образуют сложную сеть взаимосвязанных элементов с шестью тематическими кластерами. Первый кластер, который на понятийной карте выделен красным цветом, связан с психоанализом (и его частной формой реляционным психоанализом/психоанализом отношений), в рамках которого поднимаются вопросы изучения гендера, интерсубъективности, тела, сексуальности, контрпереноса и пр. Второй кластер (зеленый цвет) фокусируется вокруг таких видов психотерапии, как социально-конструкционистская семейная терапия и нарративная терапия, включая, соответственно, термины «супервизия», «конструктивизм», «герменевтика» и пр. Главная тема третьего кластера (синий цвет) - эпистемология. В него входит и одно из ключевых понятий философии постмодернизма - «нарратив». Четвертый кластер (желтый цвет) связан с изучением идентичности, а также таких смежных феноменов, как самость, агентность и рефлексивность. Проблемы современной культуры являются фокусом пятого кластера (фиолетовый цвет). В него входят такие понятия, как «культура», «современность», «глобализация», «культура потребления» и пр. Шестой и последний кластер (голубой цвет) касается карьеры («карьерное консультирование» и «построение карьеры»).

Понятийная карта включает имена четырех ученых: З. Фрейд, М. Фуко (входят в первый кластер), К.Г. Юнг (второй кластер) и Л.С. Выготский (третий кластер).

\footnotetext{
${ }^{2}$ Цветной вариант понятийной карты доступен по ссылке https://fedleks.ru/suppl/colour_2021.pdf
} 
Рисунок 2

Понятийная карта ключевых слов психологических публикаций, касающихся постмодернизма (1978-2018)

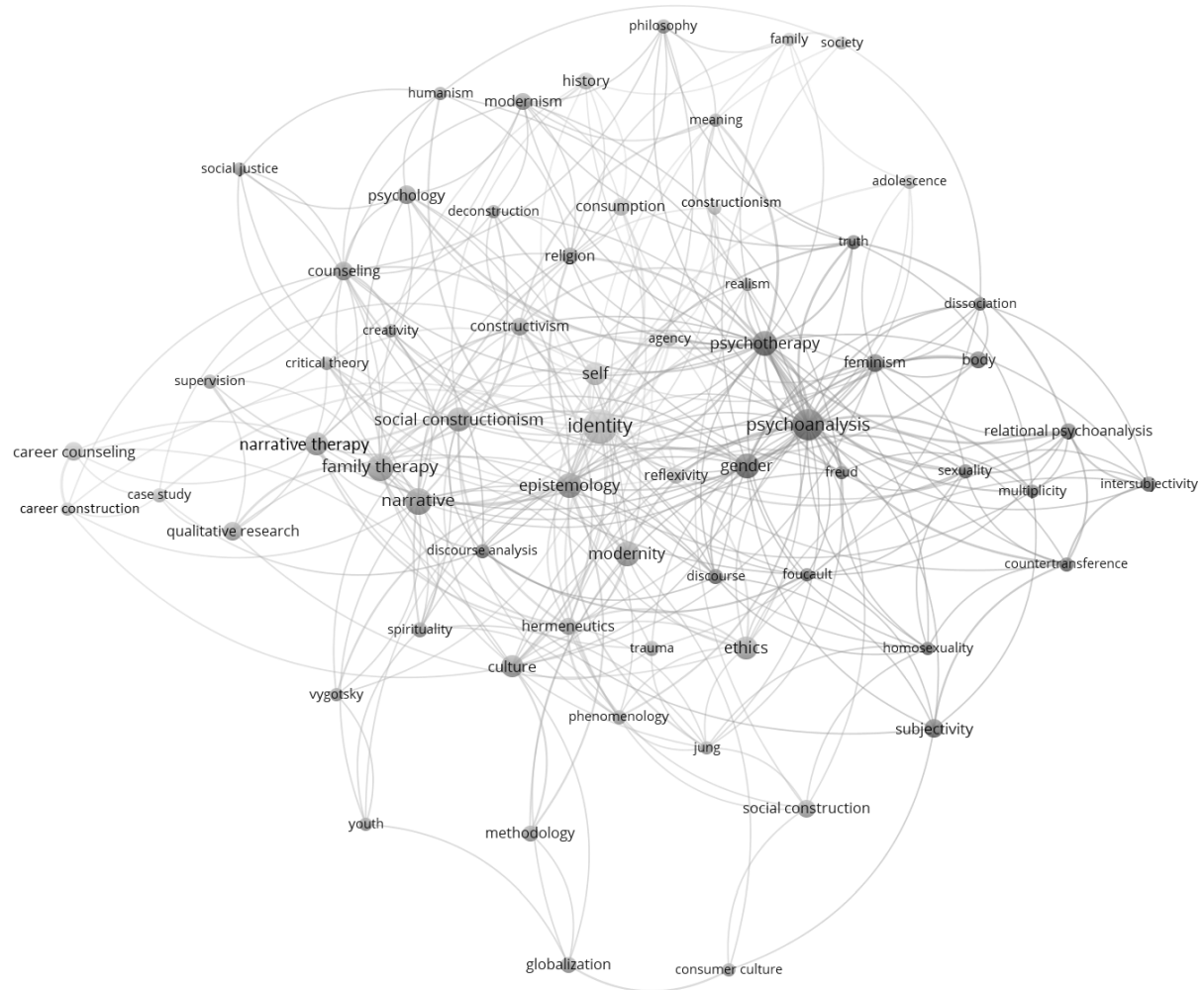

Примечательно, что все имена характеризуются одинаковой частотой вхождения в список авторских ключевых слов $(\mathrm{n}=7)$.

Согласно полученной понятийной карте, основными психологическими направлениями, в которых используются постмодернистские идеи, являются психоанализ и социальный конструкционизм.

\section{Страны и языки}

В целом психологические публикации, имеющие отношение к постмодернизму, написаны авторами, которые представляют 57 стран. В таблице 1 приведены 10 наиболее продуктивных по этому показателю стран вместе с таким показателем, как число статей на 1 миллион жителей.

Первые три страны (США, Великобритания и Канада) генерируют практически $2 / 3$ количества психологических публикаций $(61.8 \%)$, имеющих отношение к постмодернизму. Это отчасти можно объяснить тем, что в Scopus 
индексируются прежде всего издания, выходящие на английском языке. Последнее также объясняет тот факт, что на английском языке написана бо́льшая часть публикаций, вошедших в базу исследования ( $\approx 89 \%)$. Вторым языком по этому показателю является французский $(\approx 4 \%)$.

Представители России - авторы 16 психологических статей, в которых затрагивается феномен постмодернизма, т.е. менее $1 \%$ от общего количества $(\approx 0.8 \%)$.

\section{Анализ авторов и изданий}

Документы, выделенные в отрасли знания «Психология», были написаны 2361 автором, при этом 88\% из них имеют не больше одной публикации, 5 и более публикаций имеют около 1\% авторов (см. таблицу 2).

Полученные данные свидетельствуют о том, что продуктивность и цитируемость авторов не являются зависимыми величинами. По соотношению количества цитирований к общему количеству публикаций, что можно рассматривать как некий показатель «эффективности», на первом месте находится К. Герген․ В этом списке четвертую позицию по продуктивности и вторую по цитируемости и индексу C/N занимает Барбара Хелд, критикующая постмодернизм в психологии и психотерапии (Held, 1995, 2001, 2003).

Если анализировать только журнальные публикации, список авторов выглядит несколько иначе (см. таблицу 3).

В этом случае К. Герген продолжает оставаться наиболее эффективным автором, а Б. Хелд находится на третьей позиции по всем трем параметрам. Первое место по продуктивности и последнее по эффективности в таблицах 2

Таблица 1

10 стран, лидирующих по числу психологических публикаций, имеющих отношение к постмодернизму

\begin{tabular}{|c|l|c|c|}
\hline Ранг & \multicolumn{1}{|c|}{ Страна } & $\begin{array}{c}\text { Число статей на 1 млн } \\
\text { жителей (N; \%) }\end{array}$ & $\begin{array}{c}\text { Количество публикаций } \\
(\mathbf{Z})\end{array}$ \\
\hline 1 & США & $819(43.3 \%)$ & 2.46 \\
\hline 2 & Великобритания & $228(12.1 \%)$ & 3.36 \\
\hline 3 & Канада & $121(6.4 \%)$ & 3.35 \\
\hline 4 & Австралия & $70(3.7 \%)$ & 2.76 \\
\hline 5 & Германия & $63(3.3 \%)$ & 0.76 \\
\hline 6 & Франция & $61(3.2 \%)$ & 0.89 \\
\hline 7 & ЮАР & $47(2.5 \%)$ & 0.86 \\
\hline 8 & Италия & $44(2.3 \%)$ & 0.74 \\
\hline 9 & Бразилия & $37(1.9 \%)$ & 0.18 \\
\hline 10 & Испания & $37(1.9 \%)$ & 0.80 \\
\hline
\end{tabular}

${ }^{3}$ При возможном расширении информационной базы исследования, путем включения в нее публикаций по социальному конструкционизму (см. последний раздел данной статьи), К. Герген выходит на первое место по числу публикаций $(\mathrm{N}=14)$, а его отрыв от других авторов по показателю эффективности становится еще значительней (C/N = 191). 
Таблица 2

Пять авторов, имеющих наибольшее количество психологических публикаций, связанных с постмодернизмом

\begin{tabular}{|c|l|l|c|c|c|c|}
\hline Ранг & \multicolumn{1}{|c|}{ Автор } & Страна & $\begin{array}{c}\text { Количество } \\
\text { публикаций (N) }\end{array}$ & $\begin{array}{c}\text { Количество } \\
\text { цитирований (C) }\end{array}$ & $\mathbf{C / N}$ & Индекс Хирша \\
\hline 1 & J.G. Maree & ЮАР & 11 & 44 & 4 & 10 \\
\hline 2 & К.J. Gergen & США & 9 & 774 & 86 & 33 \\
\hline 3 & H. Anderson & США & 8 & 175 & 21.9 & 12 \\
\hline 4 & В.S. Held & США & 7 & 252 & 36 & 11 \\
\hline 5 & R. Frie & Канада & 7 & 23 & 3.3 & 9 \\
\hline
\end{tabular}

Таблица 3

Пять авторов, имеющих наибольшее количество журнальных публикаций, связанные с постмодернизмом

\begin{tabular}{|c|l|l|c|c|c|c|}
\hline Ранг & \multicolumn{1}{|c|}{ Автор } & Страна & $\begin{array}{c}\text { Количество } \\
\text { публикаций (N) }\end{array}$ & $\begin{array}{c}\text { Количество } \\
\text { цитирований (C) }\end{array}$ & С/N & $\begin{array}{c}\text { Индекс } \\
\text { Хирша }\end{array}$ \\
\hline 1 & J.G. Maree & ЮАР & 11 & 44 & 4 & 10 \\
\hline 2 & K.J. Gergen & США & 9 & 774 & 86 & 33 \\
\hline 3 & B.S. Held & США & 7 & 252 & 36 & 11 \\
\hline 4 & R.T. Hare-Mustin & США & 6 & 363 & 60.5 & 16 \\
\hline 5 & F.C. Richardson & США & 6 & 101 & 16.8 & 13 \\
\hline
\end{tabular}

и 3 занимает южноафриканский психолог Дж.Г. Мари, в фокусе исследовательских интересов которого находится карьерное консультирование (шестой кластер понятийной карты).

Анализируемые журнальные публикации (n = 1687, документы из других источников в этой части анализа не учитывались) были изданы в 438 журналах, при этом пять и более статей опубликовано в 98 журналах ( $\approx 22 \%)$. В 41\% журналов содержится лишь одна статья, имеющая отношение к постмодернизму. В таблице 4 представлены 10 журналов, лидирующих по количеству упоминаний постмодернизма.

В двух журналах (American Psychologist, American Behavioral Scientist) публикуются психологические статьи широкого профиля; три журнала посвящены проблемам семейной терапии (Journal of Family Therapy, Family Process, Contemporary Family Therapy); два освещают вопросы теоретической психологии (Theory \& Psychology, Journal of Theoretical and Philosophical Psychology) и три журнала посвящены отдельным направлениям внутри психологии: пастырской психологии (Pastoral Psychology), символическому интеракционизму (Symbolic Interaction) и аналитической психологии К.Г. Юнга (Journal of Analytical Psychology). Несмотря на то что самым объемным кластером понятийной карты является кластер, связанный с психоаналитической психологией, 
Таблица 4

Пять авторов, имеющих наибольшее количество психологических публикаций, связанных с постмодернизмом

\begin{tabular}{|c|l|c|c|c|c|}
\hline Ранг & \multicolumn{1}{|c|}{ Журнал } & $\begin{array}{c}\text { Количество } \\
\text { публикаций (N) }\end{array}$ & $\begin{array}{c}\text { Количество } \\
\text { цитирований (C) }\end{array}$ & C/N & SJR 2017 \\
\hline 1 & Theory \& Psychology & 54 & 693 & 12.83 & 0.434 \\
\hline 2 & Journal of Family Therapy & 34 & 574 & 16.88 & 0.776 \\
\hline 3 & American Psychologist & 33 & 1938 & 58.73 & 1.594 \\
\hline 4 & Pastoral Psychology & 28 & 52 & 1.86 & 0.248 \\
\hline 5 & Symbolic Interaction & 27 & 821 & 30.41 & 0.549 \\
\hline 6 & $\begin{array}{l}\text { Journal of Theoretical and } \\
\text { Philosophical Psychology }\end{array}$ & 26 & 127 & 4.88 & 0.351 \\
\hline 7 & Family Process & 25 & 773 & 30.92 & 1.075 \\
\hline 8 & $\begin{array}{l}\text { Journal of Analytical } \\
\text { Psychology }\end{array}$ & 24 & 131 & 5.46 & 0.246 \\
\hline 9 & American Behavioral Scientist & 23 & 269 & 11.70 & 0.982 \\
\hline 10 & Contemporary Family Therapy & 23 & 121 & 5.26 & 0.413 \\
\hline
\end{tabular}

лишь один специализированный психоаналитический журнал вошел в перечень наиболее продуктивных изданий. Это указывает на отсутствие единого публикационного центра: психоаналитические статьи, имеющие отношение к постмодернизму, представлены в самых разнообразных журналах. В списке изданий, в которых опубликовано пять и более статей по теме, находятся 15 журналов, название которых прямо указывает на психоанализ ( $\approx 15 \%$ ).

Также отметим, что существует значимая положительная корреляция между $\mathrm{SJR}^{4}$ и показателем $\mathrm{C} / \mathrm{N}\left(r_{\mathrm{S}}=0.84, p=0.002\right)$.

\section{Возможные ограничения исследования}

Возможным ограничением проведенного исследования (помимо небезупречности самой базы данных) может быть то, что в нем учитывались только публикации, открыто указывающие на постмодернизм в своем названии, аннотации или ключевых словах. В составленную таким образом базу не попадает, например, значительная часть статей, посвященных социальному конструкционизму, который часто рассматривают как постмодернистское движение 5 . Общий ответ в данном случае сводится к тому, что социальный

${ }^{4}$ SCImago Journal Ranking (SJR) представляет собой разработанный Университетом Гранады рейтинг журналов, в котором наряду с общим количеством цитирований учитываются и другие показатели, например авторитетность ссылок.

${ }^{5}$ Так, в предметной области «Психология» базы Scopus указание на постмодернизм содержит примерно 10\% статей, отобранных по признаку наличия словосочетания «social constructionism» в названии, аннотации или ключевых словах (56 из 544 за период 1985-2018 гг.). 
конструкционизм и постмодернизм представляют собой хотя и близкие по духу, но не тождественные движения. Так, У. О’Донохью предлагает говорить не об одном направлении, а о «семейном древе постмодернистов, социальных конструкционистов, постструктуралистов, герменевтиков, радикальных феминистов и современных социологов науки и технологии» (O’Donohue, 2013, p. 119) ${ }^{6}$. А. Алвессон и К. Сколдберг пишут, что «социальный конструкционизм довольно часто связывают с постмодернизмом, и хотя это и может быть верным на поверхностном уровне, их корни и фундаментальные принципы различны» (Alvesson, Sköldberg, 2009, p. 15). Дж. Хрёби предлагает выделять «три волны» социального конструкционизма, из которых лишь вторая, связанная с подходом К. Гергена, является постмодернистской (Hruby, 2001) ${ }^{7}$. Интересно, что третья волна вообще порывает с антиреализмом и основывается на «новом реализме» (или неонатурализме). Можно отметить, что при включении в поисковый запрос «социального конструкционизма», в него также нужно будет добавить постструктурализм, герменевтику, радикальный феминизм и прочие движения, что, учитывая их нежесткие связи с постмодернизмом, приведет к размыванию изучаемого предмета. Таким образом, ограничение исследования публикациями, открыто указывающими на постмодернизм, представляется оправданным и оставляет открытым для наукометрического и теоретического анализа вопрос о связи постмодернистской психологии с другими представителями этого «интеллектуального семейного древа».

\section{Заключение}

Насколько нам известно, это первое библиометрическое исследование, посвященное феномену постмодернизма в психологии. Проведенный наукометрический анализ позволяет утверждать, что, хотя взрывной рост психологических публикаций, посвященных постмодернизму, закончился, этот феномен продолжает вызывать устойчивый, хотя и несколько угасший, интерес исследователей в различных областях психологии. При этом усилия исследователей направлены не только на защиту основных положений постмодернистской психологии, но и на критический анализ, вскрывающий ее недостатки и ограничения.

Психоанализ и социальный конструкционизм не только стали точками проникновения постмодернистских идей в психологическую науку, но и продолжают оставаться направлениями, в которых постмодернизм пользуется наибольшей популярностью.

В заключение еще раз отметим, что хотя с теоретической точки зрения вопрос о том, можно ли рассматривать постмодернистскую психологию

\footnotetext{
${ }^{6}$ При этом есть и исследователи, использующие постмодернизм как понятие, объединяющее другие (см.: Woolfolk, 1992).

${ }^{7}$ Включение в базу статей, указывающих либо на постмодернизм, либо на социальный конструкционизм К. Гергена (запрос: TITLE-ABS-KEY(postmodern* OR post-modern* OR ("social constructionism” and gergen)) AND PUBYEAR < 2019 AND ( LIMIT-TO ( SUBJAREA,»PSYC»)), сказывается на количестве документов весьма незначительно ( $\approx 1 \%)$.
} 
вообще как манифестацию постнеклассической рациональности, остается открытым ${ }^{8}$, наукометрический анализ показывает, что постнеклассика per se в психологических публикациях, связанных с постмодернизмом, представлена весьма незначительно. Из 1892 документов, вошедших в базу исследования, только в пяти содержится указание на постнеклассику в названии, аннотации или ключевых словах (0.26\%), и все эти статьи написаны российскими авторами. Постмодернизм же как таковой остается интересен довольно широкому кругу исследователей разных стран.

\section{Литература}

Гусельцева, М. С. (2016). Принцип развития в психологии: вызовы полипарадигмальности и трансдисциплинарности. В кн. А. Л. Журавлев, Е. А. Сергиенко (ред.), Приниип развития в современной психологии (с. 31-51). М.: Изд-во «Институт психологии РАН».

Гусельцева, М. С. (2018). Метамодернизм в психологии: новые методологические стратегии и изменения субъективности. Вестник Санкт-Петербургского университета. Психология, 8(4), 327-340. https://doi.org/10.21638/11701/spbu16.2018.402

Журавлев, А. Л., Юревич, А. В. (2007). Введение. В кн. А. Л. Журавлев, А. В. Юревич (ред.), Теория и методология психологии: Постнеклассическая перспектива (с. 7-12). М.: Изд-во «Институт психологии РАН».

Ловаков, А. В. (2017). Российские авторы в ведущих международных психологических журналах: библиометрический анализ. Психология. Журнал Высшей школы экономики, 14(4), 657-678. https://doi.org/10.17323/1813-8918-2017-4-657-678

Патяева, Е. Ю. (2018). Классическое, неклассическое и постнеклассическое знание в современной психологии. В кн. А. Л. Журавлев, А. В. Юревич (ред.), Психологическое знание: Современное состояние и перспективы развития (с. 160-193). М.: Изд-во «Институт психологии РАН».

Фёдоров, А. А. (2018а). Библиометрический анализ публикаций по постнеклассической психологии в Scopus. Reflexio, 11(1), 37-46. https://doi.org/10.25205/2658-4506-2018-11-1-37-46

Фёдоров, А. А. (2018б). Типы научной рациональности в психологии: критика подходов. Вопросы психологии, 6, 88-99.

Ссылки на зарубежные источники см. в разделе References после англоязычного блока.

Фёдоров Александр Александрович - заведующий кафедрой, кафедра клинической психологии, Институт медицины и психологии, Новосибирский государственный университет, кандидат психологических наук.

Сфера научных интересов: философия и история психологии, современный бихевиоризм, психология морального поведения.

Контакты: fedleks@yandex.ru

\footnotetext{
${ }^{8}$ Существование «постмодернистского варианта» постнеклассической психологии (Фёдоров, 2018б) с необходимостью не означает ни того, что всякая постмодернистская психология воплощает постнеклассическую рациональность, ни того, что постмодернизм является «методологическим китом» всей постнеклассической психологии.
} 


\title{
Postmodernism in Psychology: a Bibliometric Analysis
}

\author{
A.A. Fedorov ${ }^{\mathrm{a}}$ \\ ${ }^{a}$ Novosibirsk State University, 1 Pirogova Str., Novosibirsk, 630090, Russian Federation
}

\begin{abstract}
The aim of the article is to conduct a bibliometric analysis of psychological publications indexed in Scopus that discuss postmodernism (both in positive and negative way), or use its ideas to analyze different phenomena. The freely distributed program VOSviewer was used to analyze and visualize the results obtained. In total, 1892 publications related to postmodernism were identi ed for the subject area "Psychology". It has been shown that psychoanalysis can be considered as the "locus of penetration" of postmodernism into psychological science. Since 1997, the number of psychological publications related to postmodernism has been stabilized in the range from 60 to 80 items per year. Six thematic clusters are highlighted by constructing the terms map based on keyword analysis. It is shown that the main psychological areas in which postmodern ideas are used are psychoanalysis and social constructionism. Three countries (USA, UK and Canada) shared almost two thirds $(61,8 \%)$ of psychological publications related to postmodernism. The most cited and effective author in this field is K. Gergen. It is concluded that although the explosive growth of psychological publications related to postmodernism has ended, this phenomenon continues to evoke a steady, though somewhat extinguished, interest of researchers in various areas of psychology. The question of whether postmodern psychology can be viewed as a manifestation of post-nonclassical rationality remains open, but scientometric analysis shows that post-nonclassics per se is almost absent presented in psychological publications related to postmodernism.
\end{abstract}

Keywords: bibliometric analysis, postmodernism, post-nonclassical psychology, social constructionism, scientometrics.

\section{References}

Alvesson, M., \& Sköldberg, K. (2009). Reflexive methodology: New vistas for qualitative research. Los Angeles, CA; London: SAGE Publications Ltd.

Ellemers, N., van der Toorn, J., Paunov, Y., \& van Leeuwen, T. (2019). The psychology of morality: A review and analysis of empirical studies published from 1940 through 2017. Personality and Social Psychology Review, 23(4), 332-366. https://doi.org/10.1177/1088868318811759

Falagas, M. E., Pitsouni, E. I., Malietzis, G. A., \& Pappas, G. (2008). Comparison of PubMed, Scopus, Web of Science, and Google Scholar: strengths and weaknesses. The FASEBJournal, 22(2), 338-342. https://doi.org/10.1096/fj.07-9492LSF

Fedorov, A. A. (2018a). Bibliometric analysis of publications on post-nonclassical psychology in Scopus. Reflexio, 11(1), 37-46. https://doi.org/10.25205/2658-4506-2018-11-1-37-46 (in Russian)

Fedorov, A. A. (2018b). Types of scientific rationality in psychology: A critique of approaches. Voprosy Psikhologii, 6, 88-99. (in Russian) 
Flis, I., \& van Eck, N. J. (2018). Framing psychology as a discipline (1950-1999): A large-scale term co-occurrence analysis of scientific literature in psychology. History of Psychology, 21(4), 334-362. https://doi.org/10.1037/hop0000067

Gergen, K. J. (1990). Toward a postmodern psychology. The Humanistic Psychologist, 18(1), 23-34. https://doi.org/10.1080/08873267.1990.9976874

Guseltseva, M. S. (2016). Printsip razvitiya v psikhologii: vyzovy poliparadigmalnosti i transdistsiplinarnosti [The principle of development in psychology: challenges of polyparadigmality and transdisciplinarity]. In A. L. Zhuravlev \& E. A. Sergienko (Eds.), Printsip razvitiya $v$ sovremennoi psikhologii [The principle of development in contemporary psychology] (pp. 31-51). Moscow: Institute of Psychology of the RAS.

Guseltseva, M. S. (2018). Metamodernism in psychology: New methodological strategies and changes of subjectivity. Vestnik of Saint Petersburg University. Psychology, 8(4), 327-340. https://doi.org/10.21638/11701/spbu16.2018.402 (in Russian)

Held, B. S. (1995). Back to reality: A critique of postmodern theory in psychotherapy. New York, NY: W. W. Norton \& Company.

Held, B. S. (2001). Antiscientific attitudes within psychotherapy: Concluding comments. Journal of Clinical Psychology, 57(1), 53-62. https://doi.org/10.1002/1097-4679(200101)57:1<53::AID-JCLP7>3.0.CO;2-K

Held, B. S. (2003). The many truths of postmodernist discourse. Journal of Theoretical and Philosophical Psychology, 18(2), 193-217. https://doi.org/10.1037/h0091185

Hruby, G. G. (2001). Sociological, postmodern, and new realism perspectives in social constructionism: implications for literacy research. Reading Research Quarterly, 36(1), 48-62. https://doi.org/10.1598/RRQ.36.1.3

Jia, H., Zhou, S., \& Allaway, A. W. (2018). Understanding the evolution of consumer psychology research: A bibliometric and network analysis. Journal of Consumer Behaviour, 17(5), 491-502. https://doi.org/10.1002/cb.1734

Kozlowski, S. W. J., Chen, G., \& Salas, E. (2017). One hundred years of the Journal of applied psychology: Background, evolution, and scientific trends. Journal of Applied Psychology, 102(3), 237-253. https://doi.org/10.1037/apl0000192

Liu, S., \& Oakland, T. (2016). The emergence and evolution of school psychology literature: A scientometric analysis from 1907 through 2014. School Psychology Quarterly, 31(1), 104-121. https://doi.org/10.1037/spq0000141

Lovakov, A. V. (2017). Russian authors in leading international journals in psychology: a bibliometric analysis. Psychology. Journal of the Higher School of Economics, 14(4), 657-678. https://doi.org/10.17323/1813-8918-2017-4-657-678_(in Russian)

O’Donohue, W. (2013). Post-podernism, social constructionism, and the science wars. In B. W. O'Donohue (Ed.), Clinical psychology and the philosophy of science (pp. 119-134). Heidelberg: Springer. https://doi.org/10.1007/978-3-319-00185-2_7

Parker, I. (1998). Against postmodernism: Psychology in cultural context. Theory \& Psychology, 8(5), 601-627. https://doi.org/10.1177/0959354398085002

Patyaeva, E. Yu. (2018). Klassicheskoe neklassicheskoe i postneklassicheskoe znanie v sovremennoy psikhologii [Classical, nonclassical and post-nonclassical knowledge in contemporary psychology]. In A. L. Zhuravlev \& A. V. Yurevich (Eds.), Psikhologicheskoe znanie Sovremennoe sostoianie i perspektivy razvitiia [Psychological knowledge: Its contemporary state and perspectives of development] (pp. 160-193). Moscow: Institute of Psychology of the RAS. 
Pesta, B. J. (2018). Bibliometric analysis across eight years 2008-2015 of Intelligence articles: An updating of Wicherts (2009). Intelligence, 67, 26-32. https://doi.org/10.1016/j.intell.2018.01.001

Polanco-Carrasco, R., Gallegos, M., Salas, G., \& Lypez-Lypez, W. (2017). Psychology journals in Chile: History and current situation. Terapia Psicológica, 35(1), 81-93. https://doi.org/10.4067/S0718-48082017000100008 (in Spanish)

Russell, A. M. (1978). Human societies in interplanetary space: toward a fructification of the utopian tradition. Technological Forecasting and Social Change, 12(4), 353-364. https://doi.org/10.1016/0040-1625(78)90041-0

Toulmin, S. (1986). Self psychology as a "postmodern" science. Psychoanalytic Inquiry, 6(3), 459-477. https://doi.org/10.1080/07351698609533645

Tur-Porcar, A., Mas-Tur, A., Merigy, J. M., Roig-Tierno, N., \& Watt, J. (2018). A Bibliometric History of the Journal of Psychology Between 1936 and 2015. The Journal of Psychology, 152(4), 199-225. https://doi.org/10.1080/00223980.2018.1440516

Van Eck, N. J., \& Waltman, L. (2010). Software survey: VOSviewer, a computer program for bibliometric mapping. Scientometrics, 84(2), 523-538. https://doi.org/10.1007/s11192-009-0146-3

Woolfolk, R. L. (1992). Hermeneutics, social constructionism and other items of intellectual fashion: Intimations for clinical science. Behavior Therapy, 23(2), 213-223. https://doi.org/10.1016/ S0005-7894(05)80382-X

Zhuravlev, A. L., \& Yurevich, A. V. (2007). Vvedenie [Introduction]. In A. L. Zhuravlev \& A. V. Yurevich (Eds.), Teoriia i metodologiya psikhologii: Postneklassicheskaya perspektiva [Theory and methodology of psychology: Post-nonclassical perspective] (pp. 7-12). Moscow: Institute of Psychology of the RAS.

Zyoud, S. H., Sweileh, W. M., Awang, R., \& Al-Jabi, S. W. (2018). Global trends in research related to social media in psychology: mapping and bibliometric analysis. International Journal of Mental Health Systems, 12(1), 4. https://doi.org/10.1186/s13033-018-0182-6

Alexandr A. Fedorov - Associate Professor, Chair of Clinical Psychology, Institute of Medicine and Psychology, Novosibirsk State University, PhD in Psychology.

Research Area: philosophy and theory of psychology, contemporary behaviorism, psychology of moral behavior.

E-mail: fedleks@yandex.ru 